\title{
Finansal Performans ve Hisse Senedi Getirisi İlişkisi: BİST Bankacılık Endeksi Üzerine Bir İnceleme
}

\author{
Nevzat ÇALIȘ ${ }^{1}$ ve Şakir SAKARYA²
}

Öz

İşletmelerin hisse senedi getirileri ve finansal performansları arasındaki ilişki yazında çokça yer almaktadır. Bu çalışmada, BİST Bankacılık Endeksi'nde faaliyet gösteren bankaların hisse senedi getirileri ile finansal performans arasındaki ilişki incelenmektedir. Çalışmada, çok kriterli karar verme tekniklerinden PROMETHEE yöntemi kullanılmaktadır. Araştırmada 2017 yılı itibariyle işlem görmekte olan 12 bankanın 2015 - 2017 yılları arasındaki verilerinden yararlanılarak analiz yapılmışır. Finansal performansı ölçmek için kullanılan, yazında genel olarak kabul edilen 15 finansal oran hesaplanarak incelemeye alınmıştır. Analiz sonuçlarına göre finansal performans açısından en başarılı bankanın Akbank, ikinci olarak ise Garanti bankasının başarılı bir grafik çizdiği görülmüştür. Diğer bankaların finansal performans açısından istikrarlı olmadığı yıllara göre dalgalı bir grafik çizdiği ve hisse senedi getirisi ile finansal performans arasında da yıllar itibariyle anlamlı bir ilişkinin olmadığı sonucuna ulaşılmıştır.

Anabtar Kelimeler: BİST, Bankac1lık Sektörü, Finansal Performans, Promethee

\section{The Relationship Between Financial Performance and Stock Yield: An Analysing on BIST Banking Index}

\begin{abstract}
The relationships between the financial performances of the companies and stock yield are greatly in periodicals. In this study, the relationships between financial performances and stock yield of the banks dealt in Stock İstanbul Banking Indexare are analyzed. In this analysis, PROMETHEE method, one of the multi-criteria decision-making methods, is used. In this research, an analysis covers data of 12 banks between periods of $2015-2017$. As a financial performance indicator, 15 financial ratios accepted in periodicals are analyzed by calculating. According to the analysis results, in terms of financial performance, the most successful bank is Akbank and the second is Garanti Bank which has a success rate. Also it is observed that other banks are not consistent in terms of financial performance, they draw a fluctuating graph and there is no significant relationship between stock yield and financial performance by years.
\end{abstract}

Key Words: BIST, Turkey Banking Sector, Financial Performance, Promethee Method

\footnotetext{
${ }^{1}$ Dr. -Bandırma Onyedi Eylül Üniversitesi Bandırma Meslek Yüksekokulu, ncalis@bandirma.edu.tr ORCID: 0000-0002-5604-0728

2 Prof. Dr. - Balıkesir Üniversitesi İktisadi ve İdari Bilimler Fakültesi, sakarya@balikesir.edu.tr ORCID: 0000-0003-2510-7384
} 


\section{Giriş}

Türkiye Bankacılık Sektörü çağımızda medeni bankacilı̆ın ihtiyaçlarını karşılayan, bağımsız, etkin, güçlü sermayeli, düzenleyici ve denetleyici kurum ve üst kurumlar kontrolünde, her gün daha da ilerlemeye devam etmektedir. Günümüzde Türkiye Bankacillk Sektöründe dünyada ileri seviyede olan ülkelerde sunulan bankacılıkla ilgili bütün iş, işlem ve hizmetleri gerçek ve tüzel kişilere verilebilmekte ve sektördeki büyüklükleri her gün artmaktadır (Sümer, 2016, s. 1). Türk Bankacllı Sektöründe Eylül 2018 itibarılla; 32 Mevduat, 13 Kalkınma ve Yatırım, 6 Katılım Bankası olmak üzere toplam 51 banka faaliyet göstermektedir (BDDK, 2019, s. 2).

Ekonominin büyük ölçüde bankalar tarafindan oluşturulduğu dikkate alındığında, Türkiye Bankacılık Sektörünün kendinden arzu edilen görevleri yapabilmesi bakımından bir yandan güçlü, sağlam ve dayanıklı bir yapıda olması gerekirken diğer yandan yapılan uygulamaların bankalara fazla yük oluşturmaması ve bankaların hareket esnekliğini azaltmaması açısından önem arz etmektedir. Aynı zamanda bankaların kaynaklarını etkin kullanıp kullanmadığı bankacılık sektörü açısından önemli bir durumdur (Kartal, 2018, s. 7).

Kaynakları etkin olarak kullanmanın tekniklerinden birisi hisse senedi çıkarmaktır. Hisse senetleri önemli yatım araçlarından biridir. Yatırımcının hisse senedi alma hedefinden beklediği getiriye ulaşabilmesi için, hisse senetlerinin ve piyasa şartlarının iyi irdelenmesi lazımdır. Bu noktada işletmelerin temel mali tablolar yardımıyla hesaplanan mali rasyoları ile işletmelerin nakit durumu, kârlılık durumu, faaliyet yapısı ve mali durumu tespit edilebilmektedir (Cengiz ve Püskül, 2016, s. 295).

Hisse senetleri pazarının büyümesi ve düzenli bir seviyede olmasının sağlanabilmesi yatırımcıların verecekleri kararlara, kararların sağıklı olması ise hisse senedi kazançlarını etkileyen etkenlerin doğru ve anlamlı bir şekilde oluşmasına bağlıdır. Hisse senedi kazançlarını öngörmeye bağlı olarak literatürde teknik analiz, rassal yürüyüş (random walk), temel analiz ve etkin piyasalar yaklaşımları kullanılmaktadır (Kalayc1 ve Karataş, 2005, s. 146). Bu çalışmada da finansal performans ve hisse senedi getirisi ilişkisinin incelenmesi amaçlanmaktadır. Bu hedefle kullanılan ölçme tekniklerinden biri de finansal oranlardır. Performans değerlendirme kriteri ne olursa olsun karar verenler en iyi seçeneği belirlerken türlü sorunlarla karşılaşırlar. Hedef bir olsa bile seçeneklerin zıtlaşması veya birden çok seçeneğin iletişim durumunda olması karar verenleri çok kriterli karar verme tekniklerine sevk etmektedir (Çağıl, 2011, s. 261).

Seçenekler içerisinden en iyiyi belirleme aşaması için karar verme sorunlarının çözümünde yoğun olarak çok kriterli karar verme teknikleri kullanılmaktadır. Bu tekniklerin esas hedefi karar vericiye farklı seçenekler içinden en doğru olanı belirleme şansı vermektedir. Bankacilık Sektörüne has faktörler ve bilgilerin elde edilebilirliği gibi belirlenen kural ve kıstlara göre makalelerde farklı teknikler uygulanmaktadır. Şirketlerin performanslarının mali olarak belirlenmesi karar verme sorunu olarak dikkate alınmaktadır (Ünal ve Yüksel, 2017, s. 265). Bu makalede de finansal rasyolar üzerinden test edilen hisse senedi kazancı ile mali başarı arasındaki ilişki Promethee tekniğiyle incelenmiştir. Analiz, BİST Bankacılık Endeksinde olan bankalara uygulanmıştır. Çalışmanın ilerleyen bölümlerinde öncelikle literatür taraması yapılmış, veri ve teknik bölümünden sonra analiz sonuçlarına yer verilmiştir. Makale sonuç bölümü ile sonlanmaktadir.

\section{Literatür İncelemesi}

Literatürde finansal performansın ölçülmesi ile ilgili olarak başta ÇKKV yöntemleri olmak üzere diğer bazı yöntemlerle birçok çalışma yapılmışıtır. Finansal performansın ölçülmesi ile ilgili son yıllarda yapılan çalışmalardan bazıları aşağıda özetlenmiştir.

Demireli (2010) çalışmasında TOPSIS yöntemini kullanarak Türkiye'de faaliyette bulunan ve ülke çapında düzenli bir seviyede topluma hizmet eden kamu sermayeli üç bankanın 2001-2007 seneleri arasında belirlenmiş 10 adet rasyo ile finansal performansları incelenmektedir. Çalışma sonunda ülke çapında düzenli olarak çalışan devlet kaynaklı bankaların yerel ve küresel mali krizlerden zarar gördüğü, başarı skorlarının yabancı bilgilere bağlı olarak devamlı olarak dalgalanmalar oluşturduğu, bankacılık piyasasında dikkate değer bir ilerlemenin belirlenemediği tespit edilmiştir.

Çağıl (2011) Türk Bankacılık alanında faaliyete bulunan özel, devlet ve yabancı kaynaklı bankaların 2006-2010 arası dönemlerine dair mali performanslarını yaptığı çalışmada ELECTRE tekniği aracilığılla incelemiştir. Kriz anlarında bazı bankalarda sıralamada değişiklik olduğu neticesine varılmıştır. 
Atmaca (2012) ise yapmış olduğu araştırmada BİST’te faaliyet gösteren spor şirketlerinin 2003-2010 yılları arasında 14 adet mali rasyodan yararlanarak şirketlerin mali performanslarını hesaplamıştır. Makalede rasyolar, TOPSİS modeli ile irdelenmiş ve netice olarak 8 yıllık zaman periyodunda takımların yıllar itibariyle performans seviyelerine ulaşılmıştır. 2003-2010 yıllarının çoğunda Fenerbahçe Sportif Hizmetler Sanayi ve Ticaret A.Ş'nin diğer firmalara göre en iyi performansa sahip firma olduğu neticesine varılmıştır.

Ayaydın ve Karaaslan (2015) yaptıkları araştırmada siyasi belirsizliğin firmaların finansal performanslarına etkisini incelemiştir. Çalışma, 2008-2013 arası döneme ilişkin olarak; Borsa İstanbul'da (BIST) sanayi sektöründe işlem gören 147 firmayı kapsamaktadır. Politik belirsizlik ile finansal performans arasındaki bağ panel veri analizi aracilığyyla ilgili dönemdeki çeyrek verilerle incelenmektedir. Analiz neticesinde siyasi belirsizlik işareti olarak 29 Mart 2009 ve 12 Eylül 2010 seçimlerinde kullanılan parametre ile finansal performans işareti olarak kullanılan parametreler arasında istatistiki bağlamda anlamlı bir bağ bulunmazken, 12 Haziran 2011 seçiminde kullanılan parametre ile finansal performans işareti olarak değerlendirilen parametreler arasında istatistiki bağlamda olumsuz ve anlamlı bir ilişkinin olduğu sonucuna ulaşılmıştır.

Akbulut ve Rençber (2015) çalışmalarında TOPSİS yöntemini kullanarak BİST’te faaliyette bulunan yap1 sektöründeki 32 firmanın 2010-2012 yıllarını içine alan üç dönemlik pazar değeri/defter değeri rasyoları ile mali performansları kıyaslanmıştır. Çalışmada mali performansı belirlemek için 10 adet parametre ve borsa performansı için ise pazar değeri/defter değeri rasyosu hesaplanmıştır. Çalışma sonucunda firmaların mali performansları ile borsa performansları karşılaştırıldığında aralarında istatistiksel olarak anlamlı bir ilişkinin olmadığı tespit edilmiştir.

Sakarya ve Akkuş (2015) çalışmalarında hisse senetleri Borsa İstanbul (BİST)'te faaliyette bulunan ve çimento piyasasında yer alan işletmelerin 2010-2013 dönemleri arasındaki mali tabloları kullanılarak, söz konusu işletmelerin mali performansları TOPSIS metodu ile incelenmiştir. Çalışmanın bulgularına bakıldığında, geleneksel rasyolara ve nakit akış rasyolarına göre işletmelerin mali başarılarının değişiklik gösterdikleri belirlenmiştir.

Doğan, Ağca ve Karayel (2016) çalışmalarında Eşleştirilmiş (Paired) T-testi kullanarak Borsa İstanbul'da (BIST) faaliyette bulunan şirketlerin CEO değişikliğini belirleyen mali etmenleri ve CEO değişikliğinin mali başarı üzerindeki etkisini belirlemeyi amaçlamışardır. Çalışmada 2004-2012 dönemleri aralığında BİST İmalat Sanayi Endeksi'nde faaliyet gösteren 136 şirketin bilgilerinden faydalanılmıştır. Çalışmanın sonucu olarak söz konusu şirketlerinin muhasebe ve piyasa esaslı başarı işaretlerinin azalması, borçların artması, işletmenin satışlarının ve aktiflerinin azalması CEO değişiminin olasıllı̆̆ını arttırdığı belirlenmiştir. Buna ilaveten CEO değişiminin işletmelerin karlılık durumlarını olumsuz anlamda etkilediği tespit edilmiştir.

Göker ve Uysal (2017) çalısmalarında BİST’te faaliyet gösteren imalat sanayii şirketlerinin uluslararasılaşma seviyelerinin şirket performanslarına etkisinin belirlenmesi hedeflenmiştir. 187 firmanın 2008-2015 senelerine ait bilgiler ile uygulanan panel veri analizi neticesinde şirketlerin uluslararasılaşma düzeyleri ile performansları arasında ters yatay $S$ şekilde bir ilişki olduğu belirlenmiştir.

Orçun ve Eren (2017)'in çalışmalarında Borsa İstanbul'da (BİST) işlem gören teknoloji şirketlerinin mali performansları TOPSIS yöntemi kullanılarak incelenmiştir. Gerçekleştirilen inceleme sonucunda 2010-2015 yılları arasında performans açısından en başarlı şirketler sırasıyla, ASELS, LINK, ARMDA, LINK, INDES ve DGATE şeklinde gerçekleşmiştir. Ayrıca, şirketlerin ilgili dönemlere yönelik finansal performanslar sıralamaları ile borsa getiri sıralamaları da analiz edilmiş ve herhangi anlamlı bir ilisski tespit edilememiştir.

Güleç ve Özkan (2018) yaptıkları çalışmalarında 2005 - 2016 yılları arasında Borsa İstanbul'da faaliyet gösteren 16 çimento şirketinin finansal performanslarını İncelemektedir. Performans değerlendirmesinde çok kriterli karar verme yöntemlerinden birisi olan Gri İlişkisel Analiz (GİA) yöntemi kullanılmıştır. Çalışma sonuçlarına göre, çimento şirketlerinin dönemler itibariyle genel olarak kârll, etkin ve yüksek hisse senedi getirisine sahip olduğu bununla birlikte, çimento şirketlerinin GİA değerleri ile hisse senedi getirileri arasındaki ilişki son derece zayıf olduğu kanısına varılmışır. Gri İlişkisel Analiz yöntemi ve hisse senedi getirileri ile elde edilen sıralamalar birbirinden ciddi anlamda farklı olduğu sonucuna varılmıştır.

Finansal performansın ölçülmesi ile ilgili PROMETHEE yöntemi kullanılarak son yıllarda yapılan çalışmalardan bazıları ise aşağıda özetlenmiştir: 
Doumpos, Gaganis ve Pasiouras (2012) yapmış oldukları çalışmada mülkiyet ve kaza sigortacilıklarının finansal performansının tahmini ve açıklanmasını PROMETHEE yöntemini kullanarak incelemişlerdir. Çalışma sonucunda 2005-2009 yılları arasında 91 ülkede faaliyet gösteren 2000'in üzerinde hayat dışı sigorta şirketi örneğini kullanılarak, reel GSYIHH büyümesi, enflasyon ve gelir eşitsizliği gibi makroekonomik göstergelerin etkilendiği tespit edilmiş, ayrıca borsa gelişiminin performans üzerinde de olumlu etkisi olduğu sonucuna ulaşılmıstır.

Uzar (2013) yapmış olduğu çalışmada PROMETHEE tekniği aracıllğıyla Türkiye faaliyet gösteren devlet bankalarının finansal performansını (2002-2007) finansal kriz öncesi ve (2008-2012) kriz sonras1 dönemlerini 10 adet kritere göre incelenmektedir. Çalsşmada sonuç olarak, Finansal performans sıralamaları 2002-2007 ve 2008-2012 dönemleri için aynı olduğu sonucuna ulaşmışlardır.

Sakarya ve Aytekin (2013) çalısmalarında Promethee tekniği aracıllğıyla belirledikleri 10 adet rasyo ile mevduat bankalarının hisse senedi ile mali performansları arasındaki ilişkiyi ölçmüşlerdir. Makalenin sonucunda ise genel anlamda hiçbir bankanın mali performans olarak tüm yıllarda tek başına en başarılı veya en başarısız sırada olmadığı sonucuna ulaşmışlardır.

Kazan, Ertok ve Çiftçi (2015) yapmış oldukları çalışmada BİST'te listelenen yedi büyük şirketin finansal performansını karşılaştırmaktadırlar. PROMETHEE ve AHP yöntemleri, finansal performansı değerlendirmek ve 4 yıllık süre için en iyi performans gösteren firmaya karar vermek için karma bir yapıda kullanılmıştır. Çalışmada sonuç olarak TUPRS Anonim Şirketi'nin (JSC.) diğer şirketlere göre en iyi finansal performansa sahip olduğunu tespit etmişlerdir.

Çalışkan ve Eren (2016) yapmış oldukları çalışmada varlık toplamlarına bakarak söz konusu seneler arasında bilgisi bulunan 3 devlet kaynaklı mevduat bankası, 6 tane Türkiye' de faaliyet gösteren yabanc1 kaynaklı bankalar, 6 tane özel kaynaklı mevduat bankası ve 2 devlet kaynaklı kalkınma ve yatırım bankası olmak üzere toplam 17 bankanın 2010-2014 yılları arasındaki mali başarıları çok kriterli karar verme metotlarından olan PROMETHEE tekniği aracıllğ̆yla analiz edilmiştir. Çalışma sonucu en başarılı mali performansı kurumsal kaynaklı bir banka olan Ziraat Bankasının olduğu sonucuna ulaşılmıştır.

Öztürk (2017) yapmış olduğu araştırmada BİST 50'de (Borsa İstanbul 50 Endeksi) bulunan işletmeler arasından belirlenen 35 işletmenin finansal durum tablosu ve kar/zarar tablolarından alınan başarı göstergelerine bağlı olarak ve PROMETHEE tekniği kullanılarak 2013, 2014 ve 2015 yılları için finansal durum tablosu ve kar/zarar tablosu başarı sıralamaları bulunmuştur. Araştırmada, kar/zarar tablosu değerlerine bağlı olarak tespit edilen 2015 dönemi başarı sıralaması ile incelenen şirketlerin 2016 yllı hisse senedi cari piyasa değerleri arasındaki istatistiksel olarak anlamlı bir ilişki bulunduğu; buna karşın, hesaplanan diğer performans sıralamaları ile analiz edilen işletmelerin takip eden dönem cari piyasa değerleri arasında istatistiki bağlamda anlamlı bir ilişki bulunmadığ kanısına varılmıştır.

Ünal ve Yüksel (2017)'in çalışmalarında BİST Sürdürülebilirlik Endeksi'nde faaliyet gösteren bankaların hisse senedi getirileri ile mali performansları arasındaki ilişki incelenmektedir. Çalışmada, çok kriterli karar verme tekniklerinden olan PROMETHEE tekniği kullanılmaktadır. Çalışmaya dair sonuçlar ise şöyledir: Analiz edilen dönemin bütününde finansal performans başarısı olarak birinci sırada Akbank'in yer almaktadır; Hisse senedi getirileri açısından ise, bu neticeleri teyit etmediği sonucuna ulaşmışlardır. Söz konusu mali başarısına rağmen Akbank'ın hisse senedi kazançları bakımından sadece 2016 senesinde birinci iken; diğer dönemdeler de ise Vakıfbank'ın hisse senedi getirisi olarak birinci sırada olduğu sonucuna ulaşmışardır.

\section{Amaç-Kapsam ve Yöntem}

Çalışmanın bu bölümünde öncelikle çalısmanın kapsamı ve amacına daha sonra da yöntemine yer verilmiştir.

\section{Çalışmanın Kapsamı}

Türk Bankacilık Sektöründe Eylül 2018 itibarıyla; 34 Mevduat, 13 Kalkınma ve Yatırım, 5 Katılım Bankası olmak üzere toplam 52 adet banka faal olarak hizmet vermektedir. Çalışmada BİST Bankalar Endeksinde yer alan 13 bankadan 12'si incelenmiştir. TBB'nin yayınlamış olduğu Bankalarımız ve Türkiye'de Bankacıllk sistemi seçilmiş rasyolar raporlarından elde edilen verilerle söz konusu bankalar çok kriterli karar verme modellerinden birisi olan Promethee metodu aracıllğ̆yla analiz edilmiştir. 


\section{Çalışmanın Amacı}

Çalışmanın amacı, BİST Bankacılık sektöründe işlem gören bankaların 2014-2017 dönemleri arasındaki dört senelik döneme dair finansal (mali) performansları ile hisse senedi kazançları arasındaki ilişskinin ölçülmesidir. Bunun sonucunda yatırımcıların karar verme süreçlerine katkı verebilmek amaçlanmaktadır. Bankacılık sektörünün Türkiye'de finansal performansını değerlendirmek için yapılan çalışmalar incelendiğinde hem IMF mali güçlülük indeks listesi hem de CAMELS derecelendirme düzeninde uygulanan yönetim kalitesi, karllık, likidite, sermaye yeterliliği, piyasa riski göstergeleri varlık kalitesi ile BDDK'nın performans bileşenleri endeksi ve TCMB'nin bankacilık güçlülük göstergesinde olan bölümlere eşit ağırlık oranları verilmiş, bu başlıklar altında oluşan göstergeler ise grup ağırlığını değiştirmeyecek biçimde yine eşit çarpanlarla oranlanmıştır (Sakarya ve Aytekin, 2013, s. 102). Bu araştırmada kullanılan rasyolar, TBB web sayfasında (http://www.tbb.org.tr) ilan edilen mali rasyolardan alınmıştır. Belirlenen finansal oranlar ve ağırlık dağılımları tablo 1'de gösterilmiştir. Tablodan da anlaşılacağı gibi belirlenen oranların ağırlıkları eşit olarak dağıtılmıştır.

Tablo 1. Seçilen Finansal Rasyolar

\begin{tabular}{|c|c|c|c|}
\hline & Finansal Rasyolar / Formüller & Kriterler & $\begin{array}{l}\text { Kriterlerin } \\
\text { Ağırlıkları }\end{array}$ \\
\hline \multirow{3}{*}{$\begin{array}{l}\text { SERMAYE } \\
\text { YETERLİLIĞİ }\end{array}$} & Sermaye Yeterliliği Oranı & S1 & 0,06 \\
\hline & Özkaynaklar / Toplam Aktifler & $\mathrm{S} 2$ & 0,06 \\
\hline & Özkaynaklar / Mevduat + Mevduat Dișı Kaynaklar & S3 & 0,06 \\
\hline \multirow{3}{*}{ AKTİF KALİTESİ } & Toplam Krediler ve Alacaklar* / Toplam Aktifler & A1 & 0,06 \\
\hline & Takipteki Krediler (net) / Toplam Krediler ve Alacaklar* & $\mathrm{A} 2$ & 0,06 \\
\hline & Tüketici Kredileri / Toplam Krediler ve Alacaklar* & A3 & 0,06 \\
\hline \multirow{3}{*}{ LİKİDİTE } & Likit Aktifler / Toplam Aktifler & L1 & 0,06 \\
\hline & Likit Aktifler / Kısa Vadeli Yükümlülükler & L2 & 0,06 \\
\hline & Likit Aktifler / (Mevduat + Mevduat Dıș1 Kaynaklar) & L3 & 0,06 \\
\hline \multirow{3}{*}{ KARLILIK } & Ortalama Aktif Karlılığ & K1 & 0,06 \\
\hline & Ortalama Özkaynak Karlılığ1 & $\mathrm{K} 2$ & 0,06 \\
\hline & Net Dönem Karı (Zararı) / Ödenmiş Sermaye & $\mathrm{K} 3$ & 0,06 \\
\hline \multirow{3}{*}{ GELİR-GİDER YAPISI } & Özel Karșlıklar Sonrası Net Faiz Geliri / Toplam Aktifler & G1 & 0,06 \\
\hline & Toplam Gelirler / Toplam Giderler & G2 & 0,06 \\
\hline & Faiz Giderleri / Toplam Aktifler & G3 & 0,06 \\
\hline
\end{tabular}

\section{Çalışmanın Yöntemi}

Çok Kriterli Karar Verme Yöntemleri (ÇKKVY) (Preference Ranking Organization Method for Enrichment Evaluations) içinde yaygın olarak kullanılan yöntemlerden biri olan PROMETHEE yöntemi Brans (1982) tarafindan geliştirilmiş ve daha sonra Brans ve Vincke (1985) tarafından da genişletilmiştir. PROMETHEE metodunun en belirgin özelliği basit, anlaşılır olması ve kararlılık yapısıdır. PROMETHEE yönteminde yapılacak olan ilk adım kriterlerin belirlenmesidir ve bu kriterlere araştırmacılar kolaylıkla ulaşabilmektedir. PROMETHEE yönteminde sıralama problemlerini çözümlemek için iki farklı yol bulunmaktadır. Bunlardan ilki, alternatiflerin önceden belirlenerek kriterler kapsamında karşılaştırılarak PROMETHEE 1 ile kısmi önceliklerin belirlenmesi; ikinci olarak da PROMETHEE 2 ile de net önceliklerin elde edilebilmesidir (Genç ve Dinçer, 2013, s. 113).

PROMETHEE yönteminde temel olarak 7 adım bulunmaktadır (Şeker, 2018, s. 55-59; Çelik ve Ustasüleyman, 2014, s. 146-149; Ünal ve Yüksel, 2018, s. 267). Bunlar kısaca aşağıdaki gibi sıralanabilir.

Adım 1: Veri matrisinin oluşturulması; veri matrisi $\mathrm{w}=(\mathrm{w} 1, \mathrm{w} 2, \ldots, \mathrm{wk})$ ağıllıkları, $\mathrm{k}$ kriterleri $\mathrm{c}=(\mathrm{f} 1, \mathrm{f} 2$, ..., fk) şeklinde olan alternatiflere $A=(a, b, c, \ldots)$ ilişkin veri matrisi Tablo 2'deki gibidir.

Tablo 2. Veri Matrisi

\begin{tabular}{cccccc}
\hline Kriterler & $\mathbf{a}$ & $\mathbf{B}$ & $\mathbf{c}$ & $\ldots$ & $\mathbf{w}$ \\
\hline $\mathbf{f 1}$ & $\mathrm{fi}(\mathrm{a})$ & $\mathrm{fi}(\mathrm{b})$ & $\mathrm{fi}(\mathrm{c})$ & $\mathrm{W}_{1}$ \\
\hline $\mathbf{f} \mathbf{2}$ & $\mathrm{f} 2(\mathrm{a})$ & $\mathrm{f} 2(\mathrm{~b})$ & $\mathrm{f} 2(\mathrm{c})$ & $\mathrm{W} 2$ \\
\hline$\ldots$ & & & & & \\
\hline $\mathrm{fk}$ & $\mathrm{fk}(\mathrm{a})$ & $\mathrm{fk}(\mathrm{b})$ & $\mathrm{fk}(\mathrm{c})$ & $\mathrm{Wk}$ \\
\hline
\end{tabular}


Adım 2: Kriterlerin tercih fonksiyonlarının belirlenmesi: Kriterlerin yapısına ve alternatiflerin sahip olduğu ana özelliklerine göre belirlenen 6 farklı tercih fonksiyonu vardır. Bu tercih fonksiyonları şöyledir: Olağan, V-tipi, Seviyeli, Lineer, U-tipi, ve Gaussian. Makalede kriterin biçimine göre ifade edilebilecek altı adet fonksiyondan Lineer ve V-tipi tercih fonksiyonları seçilmiştir. Karar verici bir ölçüt için ortalamanın üstünde kıymete sahip seçeneklerden birini seçme talep edildiğinde Lineer fonksiyon kullanılır. Karar verici bir ölçüt için belirlenen kıymetten daha çok bir kıymete sahip olan seçeneklerden tarafa seçilmek isteniyor ama belirlediği bu kıymetin altında kalanları dikkate almak istemediği durumlarda ise V Tipi kullanılır (Ünal ve Yüksel, 2017, s. 267).

Tablo 3. Tercib Fonksiyonlar

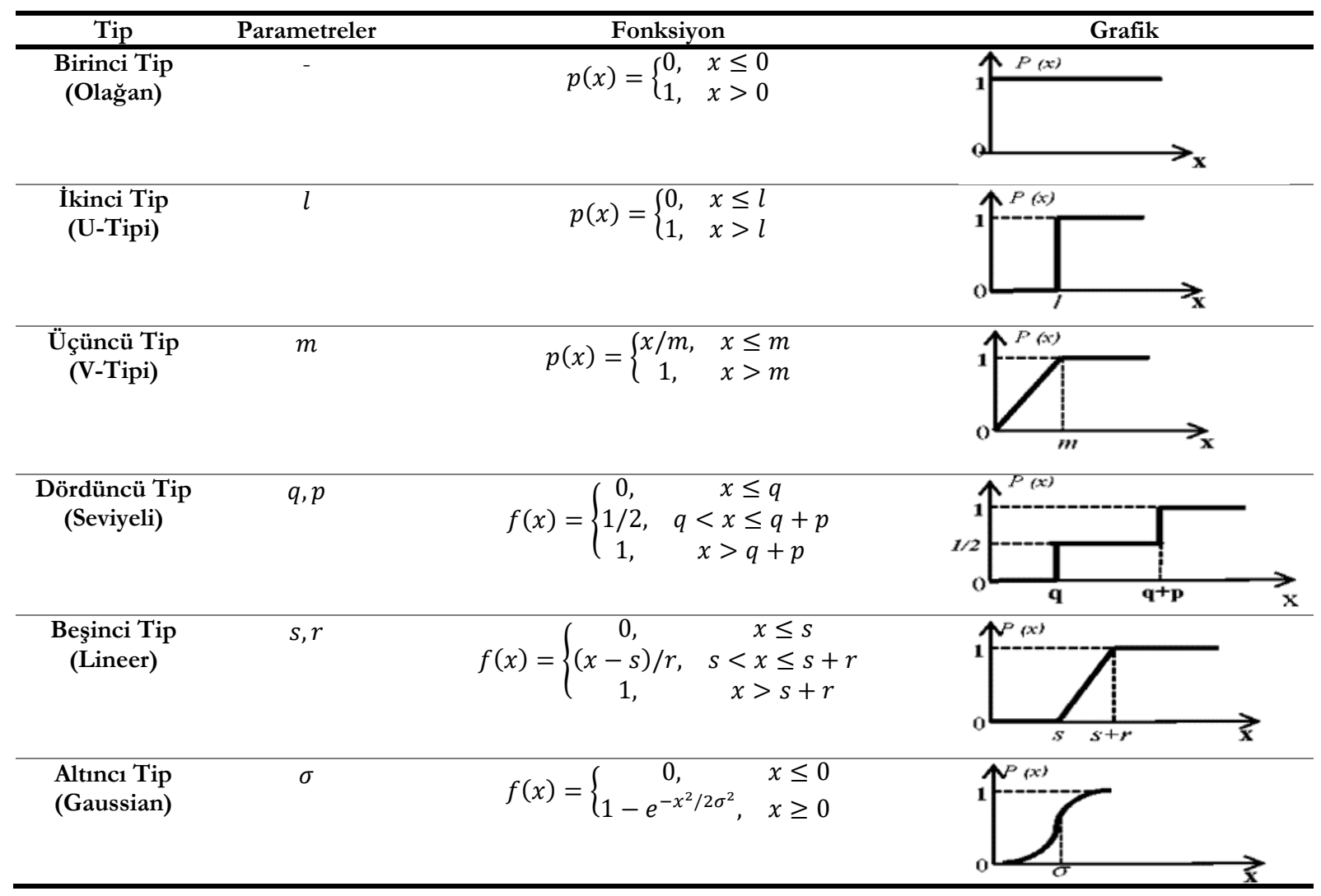

Adım 3: Tercih fonksiyonlarının belirlenmesi dikkate alınarak karar noktalarının ikili karşılaştırmaları yapılır ve bütün alternatif çiftleri için ortak tercih fonksiyonları belirlenir. A ve b alternatif tercih fonksiyonları aşağıdaki gibidir.

$$
P(a, b)=\left\{\begin{aligned}
0, & f(a) \leq f(b) \\
p[f(a)-f(b)], & f(a)>f(b)
\end{aligned}\right.
$$

Adım 4: Pozitif ve negatif üstünlük değerlerinin hesaplanması: wi (i= 1, 2, .., k) ağırlıklarına sahiptir ve k kriter tarafından değerlendirilen a ve b alternatiflerinin tercih indeksi $\pi(\mathrm{a}, \mathrm{b})$ formül ile bulunmaktadır.

$$
\pi(\mathrm{a}, \mathrm{b})=\frac{\sum_{i=1}^{k} w_{i} x P_{i}(a, b)}{\sum_{i=1}^{k} W_{i}}
$$

Adım 5: PROMETHEE I ile seçeneklerin kısmi sıralamasına ulaşılır. Ulaşılan pozitif değer $(\Phi+)$ ilgili seçeneğin diğer ihtimali olan seçeneklere nazaran ne kadar üstün olduğunu işaret ederken, negatif değer $(\Phi)$ ise başka seçeneklere nazaran ne kadar güçsüz olduğunu belirtir. Pozitif ve negatif üstünlük aşağıdaki gibi hesaplanır.

$\Phi+(\mathrm{a})=\sum \pi(\mathrm{a}, \mathrm{x}) \mathrm{x}=(\mathrm{b}, \mathrm{c}, \mathrm{d}, \ldots)$

$\Phi-(\mathrm{a})=\sum \pi(\mathrm{x}, \mathrm{a}) \mathrm{x}=(\mathrm{b}, \mathrm{c}, \mathrm{d}, \ldots)$ 
Adım 6: PROMETHEE I ile alternatiflerin birbirlerine göre öncelik değerleri hesaplanır. a ve b gibi iki farklı alternatifler için kısmi önceliklerin tespit edilmesinde aşağıdaki durumlara bakılarak karar verilir.a alternatifinin $\mathrm{b}$ alternatifine tercih edilebilmesi için aşağıda belirtilen durumlardan herhangi birinin sağlanıyor olması gerekir.

$$
\begin{aligned}
& \Phi_{+}(\mathrm{a})>\Phi_{+}(\mathrm{b}) \text { ve } \Phi \text {-(a) }<\Phi \text {-(b) } \\
& \Phi_{+}(\mathrm{a})>\Phi_{+}(\mathrm{b}) \text { ve } \Phi \text {-(a) }=\Phi \text {-(b) } \\
& \Phi_{+(\mathrm{a})}=\Phi_{+(\mathrm{b})} \text { ve } \Phi \text {-(a) }<\Phi \text {-(b) }
\end{aligned}
$$

a alternatifinin b alternatifinden farksız olması için aşağıdaki koşulun sağlanıyor olması gerekir.

$\Phi_{+}(\mathrm{a})=\Phi_{+}(\mathrm{b})$ ve $\Phi-(\mathrm{a})=\Phi-(\mathrm{b})$

a alternatifinin b alternatifi ile karşılaştırılabilmesi için aşağıdaki durumlardan herhangi birinin sağlanıyor olmas1 gerekir.

$$
\begin{aligned}
& \Phi_{+(\mathrm{a})}>\Phi_{+}(\mathrm{b}) \text { ve } \Phi \text {.(a) }>\Phi \text {-(b) } \\
& \Phi_{+(\mathrm{a})}<\Phi_{+}(\mathrm{b}) \text { ve } \Phi \text {-(a) }<\Phi \text {-(b) }
\end{aligned}
$$

Adım 7: PROMETHEE II seçenekler için hesaplanan net öncelik değerlerini (Фnet) sıralar. Elde edilen öncelik değerleri ile bütün seçenekler aynı doğruda varsayılarak tam sıralama oluşturulmaktadır.

$\Phi(\mathrm{a})=\Phi+(\mathrm{a})-\Phi-(\mathrm{a})$

a ve b gibi iki seçenek için ölçülen tam öncelik değerleri göz önünde bulundurularak aşağıdaki kararlar verilmektedir. $\Phi(\mathrm{a})>\Phi$ (b) ise, a seçeneği b seçeneğinden üstündür. $\Phi(\mathrm{a})=\Phi(\mathrm{b})$ ise, a ve b farksızdır.

\begin{tabular}{|c|c|c|c|c|c|c|c|c|c|c|c|c|c|c|c|}
\hline $\begin{array}{l}\text { KRİTERLER/ } \\
\text { BANKALAR }\end{array}$ & S1 & $\mathbf{S} 2$ & S3 & A1 & A2 & A3 & L1 & L2 & L3 & K1 & $\mathrm{K} 2$ & K3 & G1 & G2 & G3 \\
\hline Akbank T.A.Ş. & 17,0 & 12,8 & 15,8 & 60,3 & 0,1 & 22,9 & 29,8 & 56,5 & 36,8 & 2,0 & 16,1 & 151,0 & 2,8 & 155,0 & 4,0 \\
\hline $\begin{array}{l}\text { Türkiye Halk } \\
\text { Bankası A.Ş. }\end{array}$ & 14,2 & 8,3 & 9,8 & 66,6 & 0,7 & 20,1 & 23,3 & 39,8 & 27,5 & 1,3 & 14,6 & 298 & 2,2 & 131,1 & 5 \\
\hline $\begin{array}{l}\text { Türkiye Garanti } \\
\text { Bankası A.Ş. }\end{array}$ & 18,7 & 12,7 & 16 & 64,5 & 0,5 & 31,5 & 22,5 & 40,8 & 28,4 & 1,9 & 15,5 & 151 & 4 & 157,4 & 3,7 \\
\hline $\begin{array}{l}\text { Türkiye İş } \\
\text { Bankası A.Ş. }\end{array}$ & 16,7 & 11,9 & 15 & 66,3 & 0,3 & 23,5 & 24,9 & 44,3 & 31,3 & 1,6 & 14,2 & 118 & 3,1 & 142 & 4 \\
\hline $\begin{array}{l}\text { Türkiye Vakıflar } \\
\text { Bankası T.A.O. }\end{array}$ & 15,5 & 8,6 & 10,3 & 68 & 0,6 & 26,1 & 21,3 & 38,5 & 25,6 & 1,6 & 17,2 & 148,9 & 2,4 & 143,3 & 4,7 \\
\hline $\begin{array}{l}\text { Yap1 ve Kredi } \\
\text { Bankası A.Ş. }\end{array}$ & 14,5 & 10,1 & 12,9 & 65,5 & 1,1 & 26,5 & 24,8 & 44,5 & 31,6 & 1,3 & 11,9 & 83,1 & 2,2 & 140,4 & 4,1 \\
\hline Denizbank A.Ş. & 19,5 & 10,6 & 13,5 & 62,9 & 1,1 & 28,9 & 24,1 & 41,9 & 30,9 & 1,6 & 14,9 & 56,7 & 2,9 & 136,9 & 4,7 \\
\hline $\begin{array}{l}\text { ICBC Türkiye } \\
\text { Bank }\end{array}$ & 14,4 & 8,5 & 9,5 & 59,2 & 0,3 & 11,1 & 35,3 & 82,5 & 39,6 & 0,6 & 6,9 & 4,9 & 2,7 & 128 & 3 \\
\hline $\begin{array}{l}\text { Finans Bank } \\
\text { A.Ş. }\end{array}$ & 15 & 9,7 & 12,9 & 65,7 & 1 & 32 & 22,4 & 41,9 & 28,7 & 1,4 & 14,5 & 47,9 & 3,7 & 139,8 & 4,2 \\
\hline $\begin{array}{l}\text { Şekerbank } \\
\text { T.A.Ş. }\end{array}$ & 15,4 & 8,7 & 10 & 65,9 & 2,2 & 5,7 & 23,6 & 37,9 & 27,4 & 0,6 & 5,7 & 9,9 & 2,7 & 123,9 & 5 \\
\hline $\begin{array}{l}\text { Türkiye } \\
\text { Kalkınma ve } \\
\text { Yatırım Bankası } \\
\text { A.Ş. }\end{array}$ & 26,2 & 24,8 & 16,6 & 64,5 & 3,8 & 0,3 & 27,5 & 337,2 & 25,3 & 0,9 & 4 & 25,7 & 3 & 210,1 & 1,1 \\
\hline $\begin{array}{l}\text { Türkiye Sınai } \\
\text { Kalkınma } \\
\text { Bankası A.Ş. }\end{array}$ & 17 & 12,2 & 15,2 & 76,9 & 0 & 0 & 14,8 & 408,9 & 18,4 & 2,2 & 18 & 24,8 & 3,6 & 201 & 2,7 \\
\hline
\end{tabular}

\section{Bulgular}

Bundan sonraki kısımda çalışma ile ilgili veriler PROMETHEE yöntemiyle analiz edilmiş ve elde edilen sonuçlar analiz edilerek yorumlanmıştır.

Tablo 4. Kriterler ve Alternatiflere İlişkin 2017 Ylu Değerlendirme Matrisi 
Tablo 4'de gösterilen değerler ve bu oranlara atanmış ağırlıklar programa girilerek aşağıdaki sonuçlar elde edilmiştir. Şekil 1'de seçenekler için meydana getirilen kriter ağırlıklarına göre en başarılıdan en başarısıza göre bir sıralama oluşmaktadır. PROMETHEE I ile oluşturulan neticeler Akbank'ın diğer bankalara nazaran daha etkin olduğunu belirtirken hangi seçeneğin seçileceğini net olarak belirtmemektedir. Bunun için PROMETHEE II verilerine gereksinim olmaktadır. PROMETHEE II sonuçları ise aşağıdaki Şekil 2'deki gibidir. Şekil 2'den de anlaşılacağı üzere yatırımcilarına en çok hisse senedi getirisini Akbank sağlarken Garanti Bankası, İş Bankası, Türkiye Kalkınma Bankası, Türkiye Sınai Kalkınma Bankası ve Deniz Bank yatırımcısına pozitif oranda katkı sağlamaktadır. Diğer yandan yatırımcısına en az kazandıran banka Şeker Bank olmuştur. Bunun yanında Vakıflar Bankası, Finans Bank, Halk Bankası ve ICBC Türkiye Bank yatırımcısına hisse senedi getirilerinde zarar ettirmiştir. Dolayısıyla en çok tercih edilmesi gereken banka Akbank olurken en az tercih edilmesi gereken banka ise Şeker Bank olmuştur.

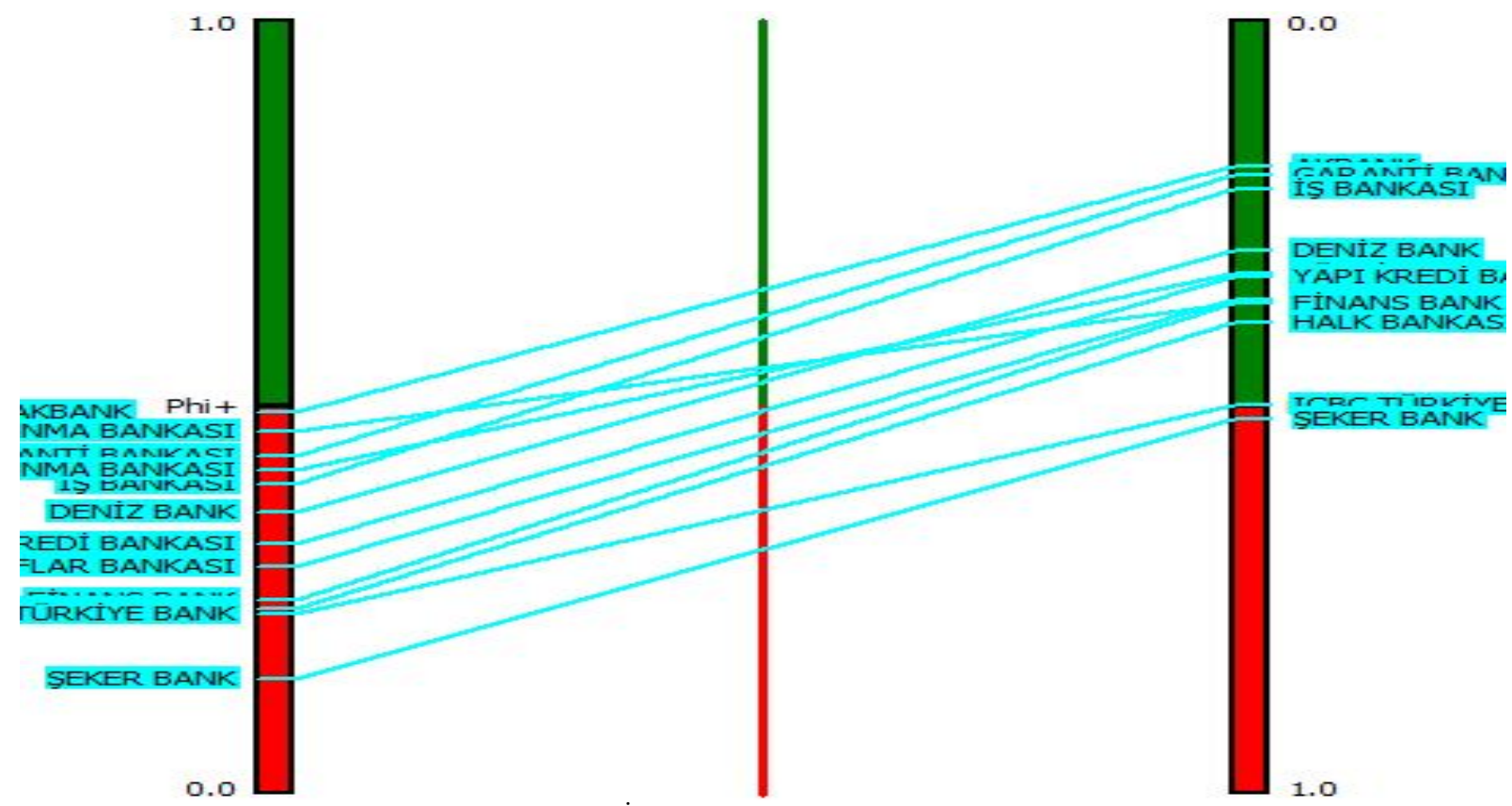

Şekil 1. 2017 Y ul İ̧̧in PROMETHEE I Siralama Sonuçar

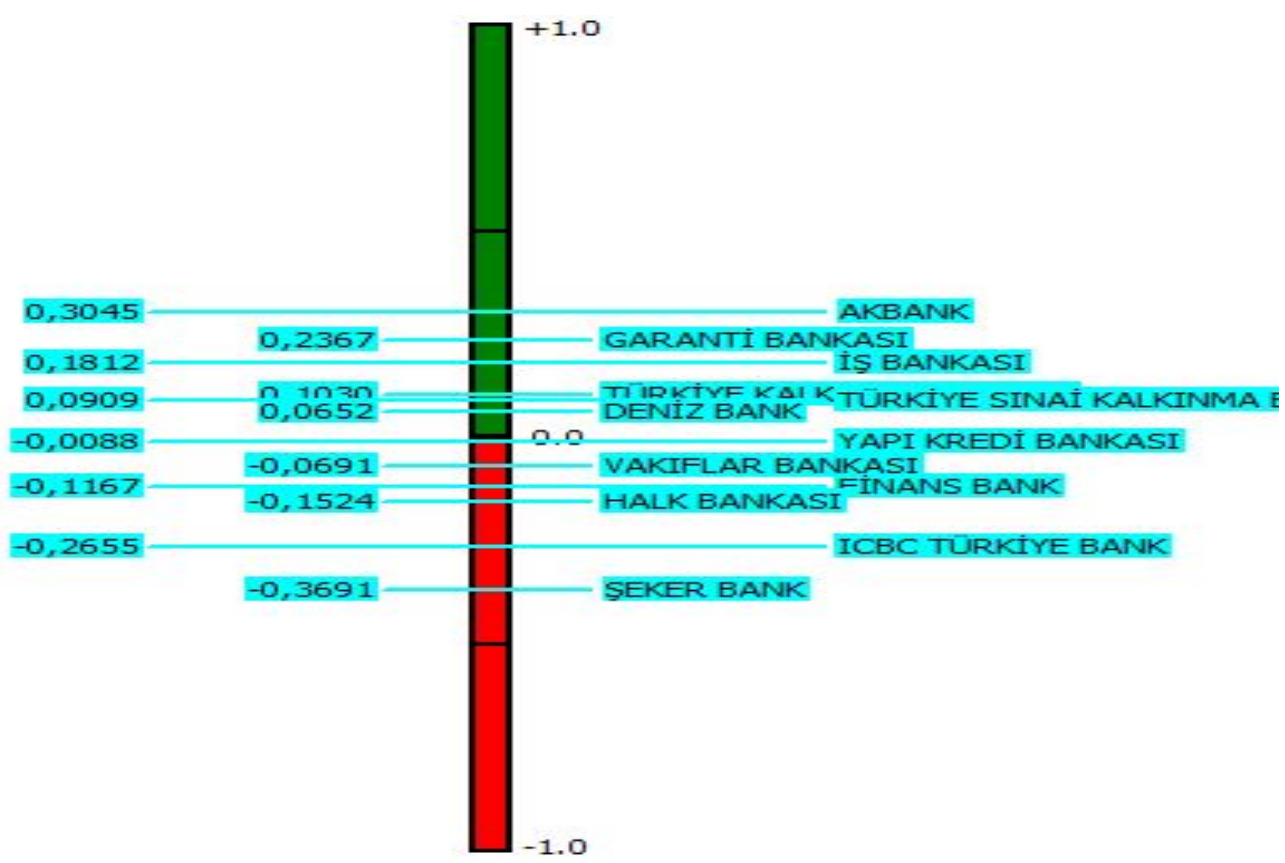

Şekil 2. 2017 Yıl İçin PROMETHEE II Suralama Sonuçar 
Karar vericinin, grafiksel gösterim yardımıyla daha sağlıklı karar vermesi için Decision Lab 2000 programında GAIA modülü bulunmaktadır. GAIA, PROMETHEE yönteminde kriter ağırlıklarının etkisini göstermek için kullanılmaktadır. Bankaların 2014-2017 y1lları arasındaki dağılımı performanslarına göre dağılımı şekil 2'de görüldügüü gibidir. Buna göre aynı tarafta ilerleyen seçenek ve kriter vektörleri uyumu, zıt tarafta ilerleyen ölçüt ve seçenek vektörleri ise uyumsuzluğu ifade etmektedir. Örneğin rasyo 11 ve rasyo 14 kriterlerine ait vektörler rasyo 15 kriteri ile ters yönde ilerlemektedir. Sonuç olarak oran 15 kriteri açısından Vakıflar Bankası, Halk Bankası ve Finans Bank seçenekleri daha başarılıdır.

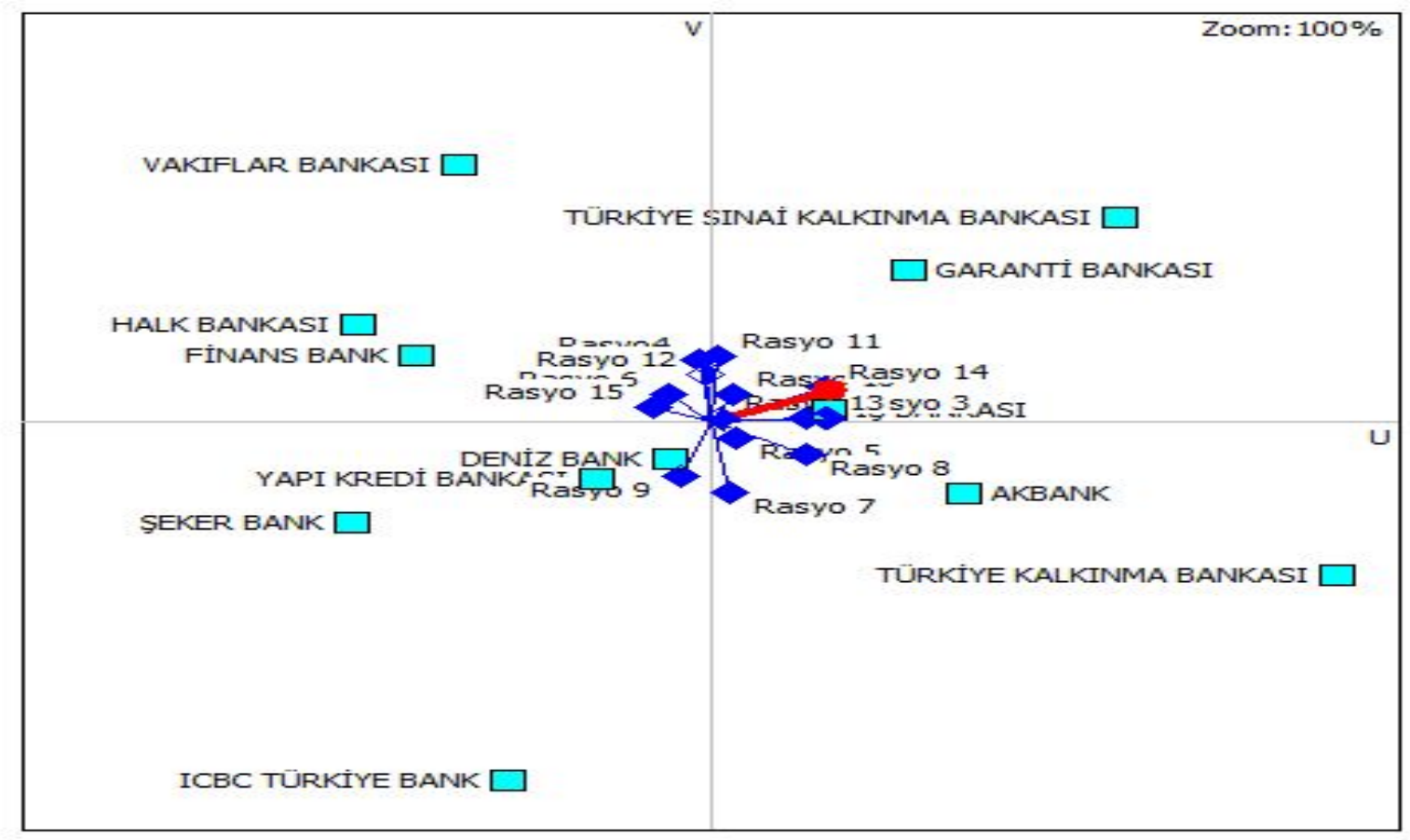

Şekil 3. 2017 Yılı İcin GALA Düqlemi

BİST’te Bankacılık Endeksinde faaliyet gösteren bankaların 2014-2017 yıllarına ait finansal performans sıralamaları Tablo 4’te aşağıda gösterilmiştir. Tablo analiz edildiğinde dört senelik süreçte Işs Bankası, Akbank ve Garanti Bankasının genel olarak üst sıralarda olduğu buna rağmen Şeker Bank, ICBC Türkiye Bank, Finans Bank ve Halk Bankası ise alt sıralarda yer aldığ1 görülmektedir.

Tablo 4. Alternatiflerin Phi (申net) Değerleri ve Siralamalar

\begin{tabular}{|c|c|c|c|c|c|c|c|c|}
\hline \multirow{2}{*}{ BANKALAR } & \multicolumn{2}{|c|}{2017} & \multicolumn{2}{|c|}{2016} & \multicolumn{2}{|c|}{2015} & \multicolumn{2}{|c|}{2014} \\
\hline & Phi $(\phi)^{\text {net }}$ & Sira & Phi $\left(\phi^{\text {net }}\right)$ & Sira & Phi $\left(\phi^{\text {net }}\right)$ & Sira & Phi $\left(\phi^{\text {net }}\right)$ & Sira \\
\hline Akbank T.A.Ş. & 0,3045 & 1 & 0,2209 & 2 & 0,1885 & 1 & 0,2506 & 2 \\
\hline Türkiye Halk Bankası A.Ş. & $-0,1524$ & 10 & $-0,1958$ & 10 & $-0,0721$ & 9 & $-0,1239$ & 10 \\
\hline Türkiye Garanti Bankası A.Ş. & 0,2367 & 2 & 0,2433 & 1 & 0,1603 & 3 & 0,0806 & 4 \\
\hline Türkiye İş Bankası A.Ş. & 0,1812 & 3 & 0,1418 & 4 & 0,1388 & 4 & 0,1173 & 3 \\
\hline $\begin{array}{l}\text { Türkiye Vakıflar Bankası } \\
\text { T.A.O. }\end{array}$ & $-0,0691$ & 8 & $-0,0121$ & 6 & $-0,0245$ & 7 & $-0,1512$ & 11 \\
\hline Yapı ve Kredi Bankası A.Ş. & $-0,0088$ & 7 & $-0,0855$ & 9 & $-0,0330$ & 8 & $-0,0361$ & 7 \\
\hline Denizbank A.Ş. & 0,0652 & 6 & 0,1979 & 3 & 0,1276 & 5 & 0,0215 & 6 \\
\hline ICBC Türkiye Bank & $-0,2655$ & 11 & $-0,2185$ & 11 & $-0,3418$ & 12 & $-0,1161$ & 9 \\
\hline Finans Bank A.Ş. & $-0,1167$ & 9 & $-0,0127$ & 7 & $-0,0839$ & 10 & $-0,0515$ & 8 \\
\hline Şekerbank T.A.Ş. & $-0,3691$ & 12 & $-0,2982$ & 12 & $-0,3261$ & 11 & $-0,3185$ & 12 \\
\hline $\begin{array}{l}\text { Türkiye Kalkınma ve Yatırım } \\
\text { Bankası A.Ş }\end{array}$ & 0,1030 & 4 & $-0,0455$ & 8 & 0,1039 & 6 & 0,0527 & 5 \\
\hline $\begin{array}{l}\text { Türkiye Sınai Kalkınma } \\
\text { Bankası }\end{array}$ & 0,0909 & 5 & 0,0642 & 5 & 0,1624 & 2 & 0,2745 & 1 \\
\hline
\end{tabular}


Genel olarak değerlendirildiğinde Akbank'in 2014 ve 2017 yllında birinci 2015 ve 2016 yllında ikinci sırada olması finansal performans açısından en başarılı banka olarak dikkat çekmektedir. Türkiye Garanti Bankası da 2014 yılında dördüncü 2015 yılında üçüncü 2016 yllında birinci 2017'de ise ikinci gelerek genel sıralamada en iyi ikinci banka olmuştur. Bu sonuçlarla en başarılı finansal performansı özel kaynaklı bir mevduat bankası sergilerken ikinciliği ise yine yabancı kaynaklı bir mevduat bankası almıştır. Çalışmada analiz edilen bankalardan Halk bankası ve Vakıflar bankası finansal performans açısından değerlendirildiğinde vasat bir görüntü sergilemiştir. Yabanc1 sermayeli bankalardan Akbank, Garanti bankası ve yerli sermayeli bankalardan İş bankası başarılı bir performans sergilerken Finans bank, Deniz bank, Yapı ve Kredi bankası ise ortalama bir performans sergilemiştir.

PROMETHEE tekniği aracıllı̆̆yla elde edilen mali başarı değerlerinin hisse senedi kazançları ile ilişsisini tespit edebilmek için ilk olarak bu bankalara dair Türk Lirası bazında aylık bileşik kazanç verileri bulunmuş ve bu verilerin yıllık ortalamaları alınmıştır. Elde edilen bulgular aşağıdaki tablo 5'de sunulmuştur.

Tablo 5. Alternatiflerin Yullık Ortalama Hisse Senedi Getiri Yüzdelerivle Siralamalar (TL)

\begin{tabular}{|c|c|c|c|c|c|c|c|c|}
\hline \multirow[b]{2}{*}{ BANKALAR } & \multicolumn{2}{|c|}{2017} & \multicolumn{2}{|c|}{2016} & \multicolumn{2}{|c|}{2015} & \multicolumn{2}{|c|}{2014} \\
\hline & $\begin{array}{c}\text { Yillik } \\
\text { Getiri } \\
\%\end{array}$ & Sira & $\begin{array}{c}\text { Y1ll1k } \\
\text { Getiri } \\
\%\end{array}$ & Sira & $\begin{array}{c}\text { Y1ll1k } \\
\text { Getiri } \\
\%\end{array}$ & Sira & $\begin{array}{c}\text { Yillik } \\
\text { Getiri } \\
\%\end{array}$ & Sira \\
\hline Akbank T.A.Ş. & 29,27 & 7 & 18,97 & 3 & $-21,21$ & 7 & 31,51 & 5 \\
\hline Türkiye Halk Bankası A.Ş. & 17,24 & 11 & $-8,45$ & 10 & $-24,26$ & 9 & 16,25 & 9 \\
\hline Türkiye Garanti Bankası A.Ş. & 45,18 & 5 & 8,76 & 7 & $-23,21$ & 8 & 37,09 & 3 \\
\hline Türkiye İş Bankası A.Ş. & 40,02 & 6 & 16,86 & 4 & $-29,89$ & 11 & 48,87 & 2 \\
\hline Türkiye Vakıflar Bankası T.A.O. & 56,77 & 3 & 14,61 & 5 & $-20,84$ & 6 & 28,77 & 7 \\
\hline Yap1 ve Kredi Bankası A.Ş. & 26,53 & 8 & 4,26 & 8 & $-31,18$ & 12 & 34,39 & 4 \\
\hline Denizbank A.Ş. & $-23,06$ & 12 & 161,03 & 1 & $-10,04$ & 5 & $-1,80$ & 11 \\
\hline ICBC Türkiye Bank & 188,80 & 1 & $-6,90$ & 9 & 38,83 & 2 & 75,70 & 1 \\
\hline Finans Bank A.Ş. & 22,11 & 10 & $-10,82$ & 11 & 92,52 & 1 & 24,24 & 8 \\
\hline Şekerbank T.A.Ş. & 55,08 & 4 & $-29,76$ & 12 & $-4,51$ & 3 & $-5,57$ & 12 \\
\hline Türkiye Kalkınma ve Yatırım Bankası A.Ş & 95,76 & 2 & 65,47 & 2 & $-28,47$ & 10 & 1,22 & 10 \\
\hline Türkiye Sınai Kalkınma Bankası & 22,96 & 9 & 10,67 & 6 & $-10,02$ & 4 & 30,94 & 6 \\
\hline
\end{tabular}

Tablo 5'deki veriler analiz edildiğinde bankaların ortalama hisse senedi kazançlarında bir dalgalanma olduğu hiçbir bankanın tüm yıllarda pozitif bir getiri sağlamadığ1 gözlenmektedir. İncelenen y1llar itibariyle yatırımcısına en çok kazandıran bankalar 2014 yılında ICBC Türkiye Bank, 2015 yllında Finans Bank, 2016 yllinda Denizbank ve 2017 yilında tekrar ICBC Türkiye Bank olmuştur. Genel sıralama olarak değerlendirdiğimizde bankaların yıllık ortalama getirilerinde bir dalgalanma söz konusudur.

Hisse senedi getirileri ile finansal performans arasında istatistiki olarak anlamlı bir ilişki olup olmadığını belirlemek için korelasyon testi uygulanmıştır. Tablo 6'da gösterilen korelasyon testi sonuçlarına göre ylllık ortalama hisse senedi getirisi ile finansal performans arasinda ( $p>0,05)$ 2014, 2015 ve 2017 yıllarında anlamlı bir ilişki olmadığı sonucuna ulaşılmışır. 2016 yllında ise yıllık ortalama hisse senedi getirisi ile finansal performans arasında $(\mathrm{p}<0,05)$ olumlu bir ilişki tespit edilmiştir.

Tablo 6. Bankalarn Hisse Senedi Getirileri ile Finansal Performanslarn Arasnndaki Korelasyon Test Sonuclarn

\begin{tabular}{|c|c|c|c|c|c|c|}
\hline & & & per2017 & per2016 & per2015 & per2014 \\
\hline & \multirow{3}{*}{ hisse2017 } & CorrelationCoefficient &,- 056 &,- 291 &,- 203 &,- 196 \\
\hline & & Sig. (2-tailed) & ,863 & ,359 &, 527 &, 542 \\
\hline & & $\mathrm{N}$ & 12 & 12 & 12 & 12 \\
\hline & \multirow{3}{*}{ hisse2016 } & CorrelationCoefficient &, $727^{* *}$ & ,630* & ,704* & ,594* \\
\hline & & Sig. (2-tailed) &, 007 & ,028 & 011 &, 042 \\
\hline \multirow{7}{*}{ Spearman'srho } & & $\mathrm{N}$ & 12 & 12 & 12 & 12 \\
\hline & \multirow{3}{*}{ hisse2015 } & CorrelationCoefficient &,- 503 &,- 172 &,- 385 &,- 294 \\
\hline & & Sig. (2-tailed) &, 095 &, 594 & 216 &, 354 \\
\hline & & $\mathrm{N}$ & 12 & 12 & 12 & 12 \\
\hline & \multirow{3}{*}{ hisse2014 } & CorrelationCoefficient & ,329 & ,249 & 207 & ,385 \\
\hline & & Sig. (2-tailed) & 297 &, 436 &, 519 &, 217 \\
\hline & & $\mathrm{N}$ & 12 & 12 & 12 & 12 \\
\hline
\end{tabular}

**. Correlation is significant at the 0.01 level (2-tailed).

*. Correlation is significant at the 0.05 level (2-tailed) 


\section{Tartışma, Sonuç ve Öneriler}

Bu çalışmada hisse senetleri BİST’te işlem gören 12 adet bankanın 2014-2017 dönemi finansal performansları PROMETHEE tekniği kullanılarak değerlendirilmiştir. Bu yıllara ait belirlenmiş 15 oran finansal performans göstergesi olarak dikkate alınmıştır. Çalışmanın çok kriterli karar verme tekniklerinden PROMETHEE yöntemi ile incelenmesi bankacılık sektörü için daha önce yapılmış olan ve bu yöntemi kullanan çalışmalarla karşılaştırma imkanı sağlamıştır. Elde edilen sonuçlar bu yöntemle aynı sektörde yapılan çalışmalarla (Sakarya ve Aytekin (2013) ve Ünal ve Yüksel (2017)) kıyaslandığında paralellik göstermektedir. Çalışma Ünal ve Yüksel (2017)'in yapmış oldukları çalısmanın bulguları ile kıyaslandığında her iki çalışmada da Akbank'ın en başarılı banka olduğu fakat tüm yıllarda hiçbir bankanın tek başına en başarılı olmadığı sonucuna varılmıştır. Aynı zamanda korelasyon analizi de finansal performans ve hisse senedi getirileri arasında istatistiksel olarak anlamlı bir ilişkinin bulunmadığı sonucu da bizim çalışmamızla paralellik göstermektedir. Çalışma (Sakarya ve Aytekin (2013)'in çalışması ile kıyaslandığında ise her iki çalışmada da hiçbir bankanın finansal performans açısından tek başına tüm yıllarda birinci sırada ya da son sırada yer almadığı görülmüştür. Finansal performans değerleri ile hisse senedi getirileri arasında gerek yıl bazında gerekse de banka bazında istatistiki olarak anlamlı bir ilişkinin olmadığı sonucuna ulaşılması bakımından da çalışmalar paralellik göstermektedir.

Çalışma bulguları genel anlamda incelendiğinde finansal performans açısından en başarılı bankanın Akbank ikinci olarak ise Garanti bankasının başarılı bir grafik çizdiği gözlemlenmektedir. Diğer bankaların finansal performans açısından istikrarlı olmadığı yıllara göre dalgalı bir grafik çizdiği görülmektedir. Yıllık hisse senedi getirileri açısından bakıldığında ise bankaların hisse senedi getirilerinin ortalamasında bir dalgalanma olduğu hiçbir bankanın tüm yıllarda pozitif bir getiri sağlamadığı gözlenmektedir. Yatırımcısına en çok kazandıran bankaların yıllar itibariyle değiştiği buna rağmen ICBC Türkiye Bank, Finans Bank ve Denizbank'ın yatırımcısına en çok hisse senedi getirisi kazandıran bankalar olduğu belirlenmiştir. İnceleme neticesinde mali başarı değerleri ile hisse senedi kazançları arasında hem yıl bakımından hem de banka bakımından istatistiki olarak anlamlı bir ilişkinin olmadığ sadece 2016 yılında mali başarı ile hisse senedi kazançları arasında anlamlı bir ilişkinin olduğu sonucuna ulaşılmışır.

\section{Etik Beyan}

"Finansal Performans ve Hisse Senedi Getirisi İlişkisi: BİST Bankacıllk Endeksi Üzerine Bir İnceleme" başlıklı çalışmanın yazım sürecinde bilimsel, etik ve alıntı kurallarına uyulmuş; toplanan veriler üzerinde herhangi bir tahrifat yapılmamış ve bu çalışma herhangi başka bir akademik yayın ortamına değerlendirme için gönderilmemiştir”.

\section{Kaynakça}

Akbulut, R. ve Rençber, Ö. F. (2015). BİST’te İmalat sektöründeki işletmelerin finansal performansları üzerine bir araştrima. Mubasebe ve Finansman Dergisi, 65, 117-136.

Atmaca, M. (2012). İMKB'de işlem gören spor şirketlerinin topsis yöntemi ile finansal performans değerlendirmesi İktisat, İsletme ve Finans, 27(320), 91-108.

Ayaydın, H. ve Karaaslan, İ. (2015). Politik belirsizlikler ve finansal performans: BIST örneği. Gümüsshane Üniversitesi Sosyal Bilimler Enstitïï̈ Elektronik Dergisi, 6(13), 52-63.

BDDK, Bankacilık Düzenleme ve Denetleme Kurumu, Bankalar. https://www.bddk.org.tr/KuruluslarKategori/Bankalar/1 (Erişim Tarihi: 19.03.2019).

Cengiz, H. ve Püskül, A. S. Ö. (2016). Hisse senedi getirileri ve kârllık arasındaki ilişki: Borsa İstanbul endeksinde işlem gören işletmelerin analizi. Yalova Üniversitesi Sosyal Bilimler Dergisi, 6(12), 295-306.

Çağıl, G. (2011). 2008 küresel kriz sürecinde Türk bankacılık sektörünün finansal performansının electre yöntemi ile analizi. Maliye Finans Yažlar, 25(93), 59-86.

Çalıskan, E ve Eren, T (2016). Bankaların performanslarının çok kriterli karar verme yöntemiyle değerlendirilmesi. Ordu Üniversitesi Bilim ve Teknoloji Dergisi, 6(2), 85-107.

Çelik, P. ve Ustasüleyman, T. (2014). Electre I ve PROMETHEE Yöntemleri İle GSM operatörlerinin hizmet kalitesinin değerlendirilmesi. Uluslararasi İktisadi ve İdari İncelemeler Dergisi, 12, 137-160.

Demireli, E. (2010). TOPSIS çok kriterli karar verme sistemi: Türkiye'deki kamu bankaları üzerine bir uygulama. Girișimcilik ve Kalkınma Dergisi, 5(1), 101-112.

Doğan, M., Ağca, V. ve Karayel, M. (2016). Türkiye'de CEO değişimine etki eden faktörler ve değişiminin finansal performans üzerindeki etkisi. Business and Economics Research Joumal, 7(2), 15-27

Doumpos, M., Gaganis, C. ve Pasiouras, F. (2012). Estimating and explaining the financial performance of property and casualty insurers: A two-stageanalysis. JCC: The Business and Economics Research Journal, 5(2), 155-170. 
Genç, T. ve Dinçer, E. S. (2013). Visual analysis for multi criteria decision problems by promethee method and gaia plane: an applicatıon, determinethe level of regional socio-economic development in Turkey. Trakya Üniversitesi Sosyal Bilimler Dergisi, 15(2), 111-130.

Göker, İ. E. K. ve Uysal, B. (2017) Uluslararasılaşma düzeyi ile finansal performans ilişkisi: imalat sanayii firmaları üzerine bir araştırma. Mubasebe ve Finansman Dergisi, 76, 157-172.

Güleç, Ö. F. ve Özkan, A. (2018). Gri ilişkisel analiz yöntemi ile finansal performansın değerlendirilmesi: BİST çimento şirketleri üzerine bir araştırma. Muhasebe ve Denetime Bakıss, 18(54), 77-95.

Kalaycı, Ş., ve Karataş, A. (2005). Hisse senedi getirileri ve finansal oranlar ilişkisi: İMKB'de bir temel analiz araștırmasi. Muhasebe ve Finansman Dergisi, 27, 146-158.

Kartal, M. T. (2018). Bankaların finans sektöründeki önemi (Importance of Banks in Finance Sector). Finansal İktisat (Financial Economics), 5-27.

Kazan, H., Ertok, M., ve Çiftci, C. (2015). Application of a hybrid method in the financial analysis of firm performance. Procedia - Social and Behavioral Sciences, 195, 403-412.

Orçun, Ç. ve Eren, B. S. (2017). TOPSIS yöntemi ile finansal performans değerlendirmesi: XUTEK üzerinde bir uygulama. Journal of Accounting and Finance, 75, 139-154

Öztürk, E. (2017). Farklı finansal raporlardan elde edilen performans ölçütleri ile cari piyasa değerleri arasındaki ilişkinin belirlenmesi: BIST 50 şirketleri üzerine bir araştırma. Mali Çözüm Dergisi/Financial Analysis, 142, 45-63.

Sakarya, Ş. ve Aytekin, S. (2013). İMKB'de işlem gören mevduat bankalarının performansları ile hisse senedi getirileri arasındaki ilişkinin ölçülmesi: PROMETHEE çok kriterli karar verme yöntemiyle bir uygulama. Uluslararası Alanya İsletme Fakültesi Dergisi, 5(2), 99-109.

Sakarya, Ş. ve Akkuş, H. T. (2015). Finansal performansın ölçülmesinde geleneksel oranlar ile nakit akım oranlarının karşılaştırmalı analizi: BIST çimento şirketleri üzerine TOPSIS yöntemi ile bir uygulama. $A K \ddot{U}$ İ̈BF Dergisi, 17(1), 109-123.

Sümer, G. (2016). Türk bankacılık sektörünün tarihsel gelişimi ve ab bankacılık sektörü ile karşılaştır1lması. Gą̧i Universitesi İktisadi ve İdari Bilimler Fakültesi Dergisi, 18(2), 485.

Şeker, M. (2018). Kurumsal sürdürülebilirlik performansmmn promethee yöntemiyle ölçülmesi: Tüpras örneği (Yüksek Lisans Tezi). Bartın Üniversitesi, Sosyal Bilimler Enstitüsü, Bartın.

TBB, Türkiye Bankalar Birliği, Araştırma ve Yaymlar. https://www.tbb.org.tr/Content/Upload/Dokuman/7519/Bankalarimiz_2017.pdf (Erişim Tarihi: 19.03.2019).

Uzar, C. (2015). Financial performance test of public banks in Turkey: An application of promethee. International Journal of Economicsand Finance Studies, 5(2),1-9.

Ünal, S. ve Yüksel, R. (2017). Finansal performans ve hisse senedi getirisi ilişkisi: BİST sürdürülebilirlik endeksindeki bankalar üzerine bir inceleme. Uluslararası Yönetim İktisat ve Issletme Dergisi, 13(5), 264-270.

\section{EXTENDED ABSTRACT}

The Turkish banking sector continues to progress every day under the control of independent, effective, strong capital, regulatory and supervisory institutions and higher institutions that meet the needs of civilised banking in our age. Today, all banking related business, transactions and services offered in countries with advanced level in the world in the Turkish banking sector can be given to real and legal persons and their size in the sector increases every day (Sümer, 2016, p. 1).

As of September 2018 in the Turkish Banking Sector; A total of 51 banks operate, 32 deposits, 13 development and investment, 6 participation banks (BDDK, 2019, p. 2). Considering that the economy is largely created by the banks, the Turkish banking sector should be strong, robust and durable in terms of performing its desired tasks, while on the other hand, it is important that the practices do not impose too much burden on the banks and reduce the flexibility of the banks to act. At the same time, whether banks use their resources effectively is an important case for the banking sector (Kartal, 2018, p. 7).

One of the techniques of using resources effectively is to issue stocks. Stocks are one of the most important investment instruments. In order for the investor to achieve the return he expects from the target of buying stocks, it is necessary to examine the stocks and market conditions well. At this point, Cash status, profitability status, operating structure and financial status of the enterprises can be determined by the financial ratios calculated by the help of the basic financial statements (Cengiz ve Püskül, 2016, p. 295).

The growth and stability of the stock market depends on the decisions that investors make, while the healthy decisions depend on the correct and meaningful formation of the factors that affect the stock gains. Technical analysis, random walk, basic analysis and effective markets approaches are used in the literature in relation to predicting stock gains (Kalayc1 ve Karataş, 2005, p. 146). The aim of this study is to examine the relationship between financial performance and return on stock. One of the measurement techniques used with this goal is financial ratios. Regardless of the performance evaluation criteria, 
decision makers face a variety of problems when choosing the best option. Even if the target is one, the contrasting of options or the fact that multiple options are in contact leads the decision makers to multicriteria decision making techniques (Çağıl, 2011, p. 261).

Multi-criteria decision making techniques are used extensively in solving decision making problems in order to determine the best of options. The main goal of these techniques is to give the decision-maker the chance to determine the right one from different options. Different techniques are applied in the articles according to the rules and constraints determined, such as factors specific to the banking sector and the availability of information. Financial determination of companies ' performance is considered a decision-making issue (Ünal ve Yüksel, 2017, p. 265).

In this study, the financial performances of 12 banks whose stocks are traded at BIST are evaluated using the PROMETHEE technique. 15 rates determined for these years are taken into account as financial performance indicator. Examination of the study with the PROMETHEE method, which is one of the multi-criteria decision making techniques, has provided the opportunity to compare with the studies that have been done for the banking sector and using this method. The results are paralleled by this method compared to the studies in the same sector (Sakarya and Aytekin (2013) and Ünal and Yüksel (2017)). Yüksel Ünal and Work (2017) compared with findings in two studies of the work of Akbank's most successful bank, but no bank's most successful single in all the years was concluded. At the same time, correlation analysis parallels our study in that there is no statistically significant correlation between financial performance and stock returns. The study (compared to the study of Sakarya and Aytekin (2013), both studies showed that no bank ranked first or last in all years alone in terms of financial performance. Studies have also been parallel in terms of reaching the conclusion that there is no statistically significant relationship between financial performance values and stock returns both on a year-by-year basis and on a bank-by-Bank basis.

When the study findings are examined in general terms, it is observed that Akbank, the second most successful bank in terms of financial performance, and Garanti Bank, drew a successful chart. It appears that other banks have drawn a fluctuating chart compared to years when financial performance was not stable. In terms of annual stock returns, it is observed that there is a fluctuation in the average of the banks stock returns and no bank has achieved a positive return in all years. Although the banks that earn the most to their investors have changed over the years, it has been determined that ICBC Türkiye Bank, Finans Bank and Denizbank are the banks that earn the most share returns to their investors. The review concluded that there was no statistically significant relationship between financial success and stock gains both in terms of the year and in terms of the bank, and only in 2016, there was a significant relationship between financial success and stock gains. 